\title{
Plasma Cleaning with Alternate Gases
}

\section{Ronald Vane, Ewa Kosmowska and Michael Cable}

XEI Scientific, Inc., Redwood City, California, United States

Background The Evactron remote plasma cleaner was introduced in 1999 for cleaning SEM chambers and stages with air flowing through a hollow cathode RF plasma that produces oxygen radicals for chemical etching. Since the initial introduction of Evactron plasma cleaners over 3500 units have been sold worldwide. The original design of the classic Evactron plasma radical source (PRS) used a hollow cathode "bird cage" electrode ${ }^{1}$ inside a small vacuum chamber to excite the air plasma at $13.56 \mathrm{MHz}$ at $20 \mathrm{~W}$ max RF power. In 2017 the new, E50 PRS was introduced with an external hollow cathode around a Macor ceramic plasma chamber ${ }^{2}$ to operate at higher power. This E50 PRS allows plasma to be ignited directly from high vacuum using "pop" ignition ${ }^{3}$ without any venting or need for adjusting the Evactron system to produce plasma at cleaning pressures $1 \mathrm{mTorr}(0.13 \mathrm{~Pa})$ to $<30 \mathrm{mTorr}(4 \mathrm{~Pa})$.

In recent years there has been an increased interest in the use of alternate gas mixtures to produce plasma. Early work done at XEI showed that the hollow cathode PRS was insensitive to most gases and plasma would ignite with no adjustment to the impedance match network. Initial experiments were done using water vapor, argon/oxygen, and hydrogen gases. In 2007 quartz crystal monitors (QCM) were used to measure hydrocarbon (HC) contamination removal rates and piecemeal data was obtained on what factors affect cleaning rates. The coating and curing method for the QCMs was improved in 2013 yielding more accurate data collection and analysis using LabView Software. ${ }^{4}$

Results Our Evactron data has shown that the best cleaning rates come at pressures below that used with the original Evactron devices using roughing pumps, but at pressures below $100 \mathrm{mTorr}$ (13 Pa) higher cleaning rates ${ }^{5}$ could be obtained while pumping with the new turbomolecular pumps that replaced diffusion pumps. A cleaning pressure of $22 \mathrm{mTorr}(3 \mathrm{~Pa})$ is easily obtained with a leak rate of $10 \mathrm{sccm}$ of air into a chamber with 300 1/sec turbomolecular pumps common on a SEM. At 20 mTorr some of the best cleaning rates are seen. This was caused by longer mean free paths that minimized the loss of active species by 3 body molecular collisions. At molecular flow there is a cutoff of plasma cleaning caused when the critical dimension active species reach the dimension of the chamber and all are lost by collisions to the walls after formation. For many common gases the pressure is at about 1 mTorr with a critical dimension of about $10 \mathrm{~cm}$.

To investigate cleaning efficiency using alternate gas mixtures, the study was done using an E50 model of the Evactron Plasma De-Contaminator on a $15 \mathrm{~L}$ vacuum chamber equipped with a 230L/sec turbo molecular pump, a 14 CFM scroll pump, and a 972B dual range pressure gauge. Evactron cleaning was done using the following gases and gas mixtures: $\mathrm{O}_{2}, \mathrm{~N}_{2}$, Ar, and $\mathrm{H}_{2}$, room air, $\mathrm{O}_{2} / \mathrm{Ar}(40 \% / 60 \%), \mathrm{O}_{2} / \mathrm{N}_{2}$ (30\%/70\%), $\mathrm{Ar} / \mathrm{H}_{2}(50 \% / 50 \%), \mathrm{Ar} / \mathrm{H}_{2}(95 \% / 5 \%)$, and $\mathrm{N}_{2} / \mathrm{H}_{2}(50 \% / 50 \%)$. The cleaning rates for each gas and gas mixture were measured at 50 Watts operating power under the standard conditions multiple times and results averaged. The standard conditions are listed in Figure 1 and the results are summarized in Table 1.

The Evactron plasma cleans by gentle chemical reaction with plasma excited neutral radicals in metastable quantum states. Ion bombardment for sputter etching is minimal. Pure $\mathrm{O}_{2}$ cleans the best as expected because of a higher density of oxygen radicals. Gas mixtures with higher content of oxygen show faster 
hydrocarbon removal rates. Nitrogen and argon have limited chemical reactivity with hydrocarbons, but nitrogen metastable radicals with multiple quantum states have more ability to decompose the hydrocarbon than the single state argon metastable. This is most likely the reason why the cleaning rates were negligible when tests were conducted with plasma at 20 Watts.

Hydrogen Plasma Cleaning. Hydrogen plasma can do reduction of carbons and carbon compounds to make volatile carbon compounds. This avoids oxidation of sensitive materials in the chamber. Hydrogen mixtures with $\mathrm{N}_{2}$ and Ar were tested, had stable plasmas and are in the table. $100 \%$ Hydrogen gas from an $\mathrm{H}_{2}$ generator using electrolysis of water gave irregular results attributed to wet $\mathrm{H}_{2}$ and other factors and are not listed. On the standard hydrocarbon material in our test the Hydrogen reaction rates were slower than oxidation rates.

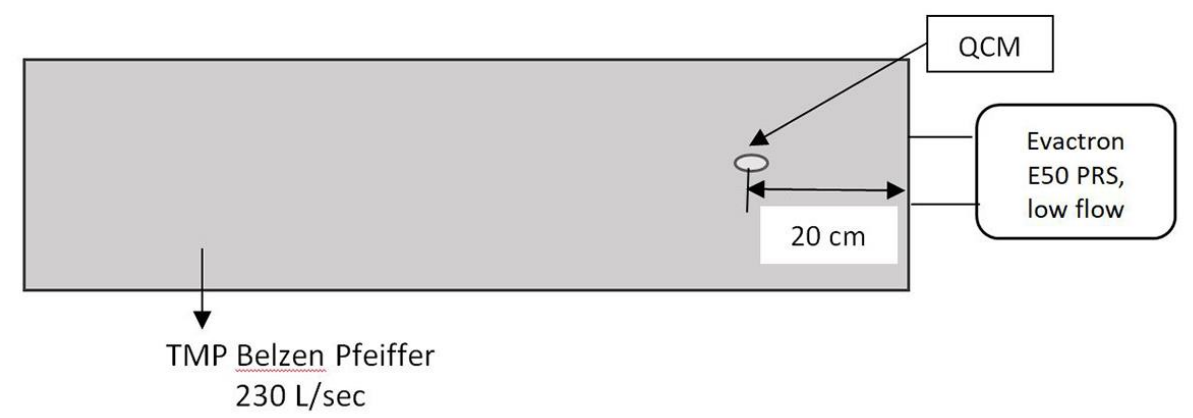

Figure 1. Standard test conditions for the experimental set up. Chamber pressure 25 mTorr (3.3 Pa)

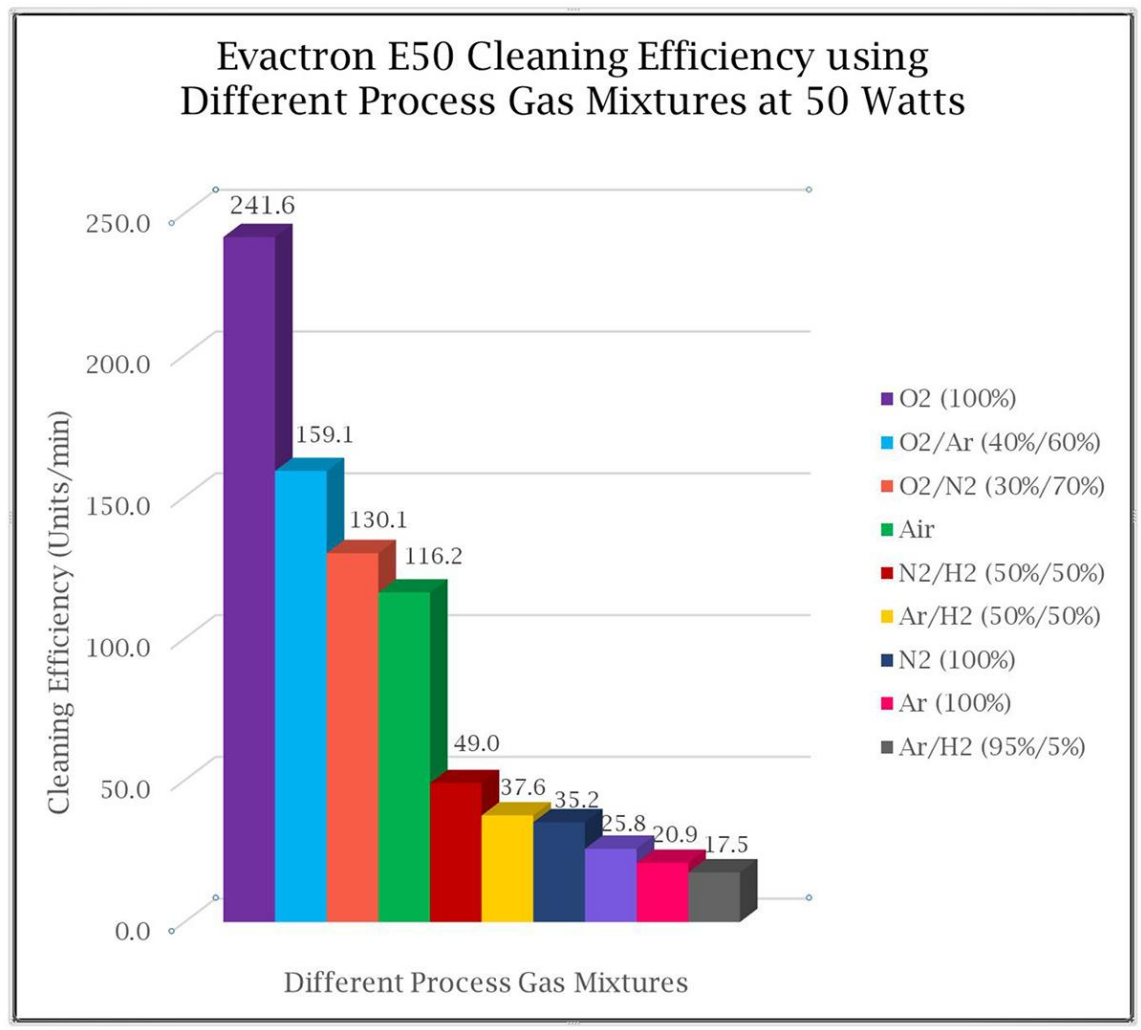

Figure 2. Evactron E50 cleaning efficiency using alternate gases. 


\section{References}

[1] US Patent 6,452,315 R. Vane (2002)

[2] US Patent 10,468,236 R. Vane (2019)

[3] E. Kosmowska et al., Microsc. Microanal. 23 (S1) (2017), 74.

[4] R. Vane et al. Microsc. Microanal. 20 (S3) (2014), 1130.

[5] R. Vane and E.Kosmowska, Microsc. Microanal. 22 (S3) (2016), 46. 